\title{
Prosthetic valve endocarditis
}

\author{
A survey
}

MOHAMED BEN ISMAIL, NAJIB HANNACHI, FEKRIA ABID, ZOUHAIR KAABAR, JEAN FRANÇOIS ROUGE

From Service des Maladies Cardio-Vasculaires, Hopital la Rabta, Tunis, Tunisia

SUMMARY Fifty eight patients (aged 8-59 years, mean 27) treated for prosthetic valve endocarditis from January 1966 to January 1985 were studied retrospectively by review of case notes. There were 12 cases of early and 46 cases of late prosthetic valve endocarditis. These developed in 28 patients with an isolated aortic valve, in 26 with an isolated mitral valve, and in four with both aortic and mitral prosthetic valves. Streptococci were the most commonly isolated microorganisms, followed by staphylococci, Gram negative bacteria, and fungi. A surgical (34 cases) or a necropsy specimen (10 cases) from 44 cases was examined. Eighty two per cent of the patients had congestive heart failure. Twenty four of the 58 patients were medically treated and 17 died (70\% mortality). Combined medical and surgical treatment was used in 34 patients; the main indication for surgery was congestive heart failure. Fourteen patients on combined treatment died ( $40 \%$ mortality). Persistent sepsis and prosthetic valve dehiscence were the most common early and late operative complications. The most important influences on outcome were congestive heart failure, the type of micro-organism, the severity and extent of anatomical lesions, the time of onset of prosthetic valve endocarditis, and the type of treatment.

This survey indicates that only patients without congestive heart failure or embolic complications and with sensitive micro-organism should be treated medically. In view of the poor prognosis patients with prosthetic valve endocarditis associated with congestive heart failure, persistent sepsis, and repeat arterial emboli should be treated by early surgical intervention.

Despite advances in antimicrobial treatment and in surgical management, postoperative endocarditis still causes considerable morbidity and mortality in patients with prosthetic heart valves. We examined the clinical course and treatment of 58 patients with prosthetic valves who presented with endocarditis over a 15 year period (1968-84).

\section{Patients and methods}

Patients treated for prosthetic valve endocarditis from January 1966 to December 1984 were studied retrospectively by review of case notes.

The diagnosis of prosthetic valve endocarditis was established by the presence of one or both of the following criteria: histopathological evidence of endocarditis in a surgical or necropsy specimen; at

Requests for reprints to Professor Mohamed Ben Ismail, Service des Maladies Cardio-vasculaires, Hopital la Rabta, Tunis, Tunisia.

Accepted for publication 11 February 1987 least two blood cultures that were positive for the same organism and associated with an obvious clinical picture of prosthetic valve endocarditis, valve dysfunction, or signs of septic emboli. Endocarditis diagnosed within 60 days of operation was classified as early, cases presenting beyond this time were classified as late endocarditis. The term active prosthetic valve endocarditis included patients with positive blood cultures in the $\mathbf{4 8}$ hours before surgical intervention, a prosthesis giving a positive culture, or a myocardial abscess found at operation or necropsy. We used the $\chi^{2}$ test for statistical analysis.

\section{Results}

Prosthetic valve endocarditis developed in 58 $(5.9 \%)(38 \mathrm{M}, 24 \mathrm{~F})$ of 979 patients with cardiac valve replacement followed by us at our hospital between January 1968 and December 1984. The age range of these 58 patients was 8-59 years (mean 27 years). There were 12 cases of early and 46 of late 
prosthetic valve endocarditis. Endocarditis developed in 28 patients with an aortic valve, in 26 with a mitral valve, and in four with combined aortic and mitral valve replacement.

\section{CLINICAL CHARACTERISTICS}

Fever was the most common clinical finding ( 55 $(95 \%))$. Other physical signs were splenomegaly (10 $(17 \%))$ and cutaneous signs $(11(18 \%))$. Anaemia, with haematocrit of $<35 \%$ and increased white cell count was detected in $50 \% ; 28 \%$ had haematuria and $16 \%$ had proteinuria. Nearly all the patients had an increased erythrocyte sedimentation rate.

\section{MICROBIOLOGY}

Table 1 shows the micro-organisms that caused prosthetic valve endocarditis in this study. These were identified by blood cultures from $34(59 \%)$ patients. Streptococci were the most commonly isolated organism, followed by staphylococci, Gram negative bacteria, and fungi. Twenty four $(41 \%)$ patients had negative blood cultures. Streptococci were more common in late prosthetic valve endocarditis, whereas more antibiotic resistant microorganisms (staphylococci, Gram negative bacteria) were more common in early prosthetic valve endocarditis. Table 2 shows the likely sources of infection in $36(62 \%)$ patients. Portals of entry were different in early and late prosthetic valve endocarditis; in late prosthetic valve endocarditis dental treatment (usually without antibiotic prophylaxis) was the most common factor indentified, followed by genital and urinary tract infection. Infections causing early prosthetic valve endocarditis occurred mainly during cardiopulmonary bypass or in the early postoperative period ( $11 / 12$ cases). Immunological investigations were performed in only four patients.

\section{ECHOCARDIOGRAPHY}

Echocardiography was performed in 18 patients.

Table 1 Microbiological causes of prosthetic valve endocarditis (PVE) in 58 patients ( 12 early cases and 46 late cases)

\begin{tabular}{|c|c|c|c|}
\hline \multirow[b]{2}{*}{ Micro-organism } & \multicolumn{3}{|c|}{ No of patients } \\
\hline & $\begin{array}{l}\text { Early PVE } \\
\text { (12) }\end{array}$ & $\begin{array}{l}\text { Late PVE } \\
(46)\end{array}$ & $\begin{array}{l}\text { Total } \\
\text { (58) }\end{array}$ \\
\hline \multirow{2}{*}{$\begin{array}{l}\text { Streptococcus } \\
\text { Staphylococcus } \\
\text { S epidermidis } \\
\text { S aureus }\end{array}$} & 1 & 13 & $14(24 \%)$ \\
\hline & $\begin{array}{l}2 \\
2\end{array}$ & $\begin{array}{l}3 \\
3\end{array}$ & $10(17 \%)$ \\
\hline \multirow{2}{*}{$\begin{array}{l}\text { Gram negative bacteria } \\
\text { Candida albicans } \\
\text { Negative blood } \\
\text { culture }\end{array}$} & $\begin{array}{l}2 \\
0\end{array}$ & $\begin{array}{l}7 \\
1\end{array}$ & $\begin{array}{l}9(15.5 \%) \\
1(1.7 \%)\end{array}$ \\
\hline & 5 & 19 & $24(41 \%)$ \\
\hline
\end{tabular}

Dehiscence of the prosthetic device was seen in two patients with aortic valve replacement and vegetations in three patients also with prosthetic aortic valves.

\section{PATHOLOGICAL CHANGES}

Examination of surgical (34 cases) or necropsy specimens (10 cases) found abnormalities in 26 aortic and 21 mitral prostheses (table 3). The most common lesions were dehiscence $(36 / 44)$ and vegetations (33/44); thromboses were more common on mitral prostheses than on aortic prostheses. The valve ring was usually considerably altered and extension of the infection to the adjacent cardiac structures was common. In the three bioprostheses that were examined infection affected the valve leaflets but not adjacent host tissue.

\section{COMPLICATIONS}

Congestive heart failure occurred in 48 patients $(82 \%)$ (12 early and 36 late cases of prosthetic valve endocarditis), neurological complications in 15 (25\%) (13 embolic strokes and two cerebral abscesses) (three early and 12 late cases of prosthetic valve endocarditis), and peripheral vascular emboli in 27 patients $(46 \%$ ) (three early and 24 late cases of prosthetic valve endocarditis).

Fever persisted in 21 patients (nine early and 12 late prosthetic valve endocarditis) after the start of appropriate medical treatment, and atrioventricular conduction disturbances with complete heart block, related to extension of the infection to the conduction system, were seen in three patients with late prosthetic valve endocarditis; six $(10 \%)$ patients with prosthetic valve endocarditis (all late cases) had renal failure.

\section{TREATMENT AND OUTCOME}

Twenty four patients had medical treatment alone; seven survived. Thirty four patients had combined medical and surgical treatment (table 4). Twenty three patients were operated on in France and 11 in Tunis.

Table 2 Sources of infection in 36 patients with prosthetic valve endocarditis (PVE)

\begin{tabular}{lllc}
\hline Portal of entry & Early PVE & Late PVE & Total \\
\hline Dental treatment & 1 & 6 & 7 \\
Cutaneous infection & & 1 & 1 \\
Urinary tract infection & & 4 & 4 \\
Pulmonary infection & & 4 & 4 \\
Genital infection & 5 & 5 \\
Gastric infection & & 2 & 2 \\
Caesarean section & & 1 & 1 \\
Post-cardiopulmonary & 11 & & 11 \\
\hline bypass & & & \\
\hline
\end{tabular}


Table 3 Pathological findings in 26 aortic and 21 mitral prostheses or bioprostheses seen at operation (34 cases) or at necropsy (10 cases)

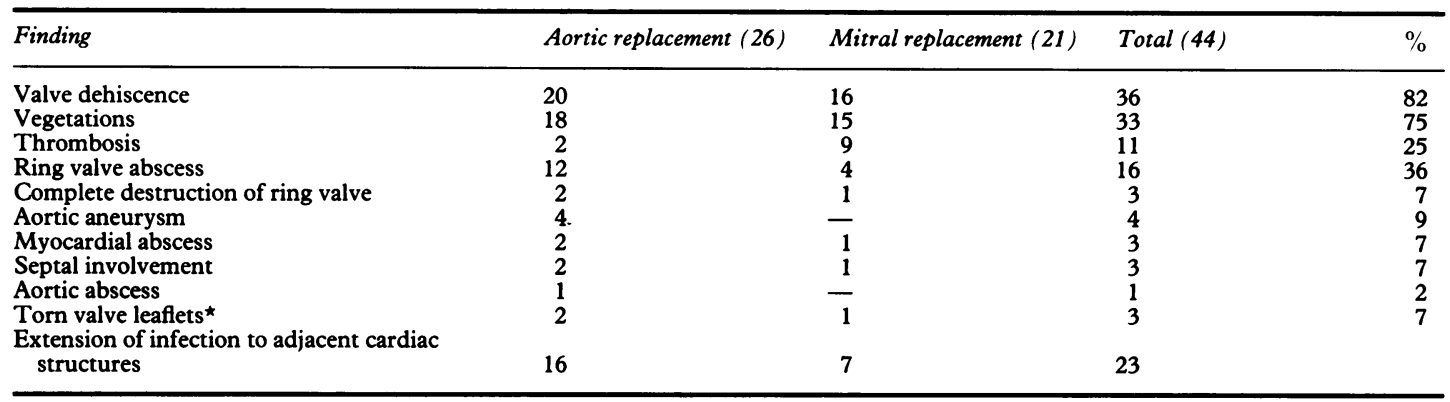

^Bioprostheses.

RESULTS OF MEDICAL TREATMENT

Of the seven patients who survived after medical treatment (one with early prosthetic valve endocarditis and six with late prosthetic valve endocarditis), two were lost to follow up and five were followed for 6-120 months (mean 64 months); all of them are alive and well-one is in grade $I$ and four in grade II of the New York Heart Association classification. The patients were not treated surgically because they responded well to medical treatment and had no obvious signs of cardiac failure or valve dysfunction. Seventeen $(70 \%)$ of the medically treated patients died. We attribute this high mortality to the fact that patients treated medically were usually referred from other hospitals, they were already critically ill, with congestive heart failure, low cardiac output, and sometimes neurological disturbances, and were too ill to undergo operation. The main cause of death was prosthetic valve dys-

Table 4 Outcome in 58 patients with prosthetic valve endocarditis

\begin{tabular}{llll}
\hline Treatment & $\begin{array}{l}\text { Total } \\
\text { No }(\%)\end{array}$ & $\begin{array}{l}\text { Survived } \\
\text { No (\%) }\end{array}$ & $\begin{array}{l}\text { Died } \\
\text { No (\%) }\end{array}$ \\
\hline $\begin{array}{l}\text { Medical/antibiotics } \\
\text { alone }\end{array}$ & $24(42)$ & $7(29)$ & $17(71)$ \\
$\begin{array}{l}\text { Medical and surgical } \\
\text { (antibiotics + } \\
\text { reoperation) }\end{array}$ & $34(58)$ & $20(59)$ & $14(41)$ \\
\begin{tabular}{l} 
Total \\
\hline
\end{tabular} & 58 & 27 & 31 \\
\hline
\end{tabular}

Table 5 Indications for surgical treatment of infected prosthetic valves

\begin{tabular}{llr}
\hline Indications & No patients & $\%$ \\
\hline $\begin{array}{l}\text { Cardiac failure (prosthetic } \\
\text { dysfunction) }\end{array}$ & 19 & 56 \\
Cardiac failure and persistent & 14 & 41 \\
$\quad$ sepsis & 1 & 3 \\
\hline Fungal PVE & 19 & \\
\hline
\end{tabular}

PVE, prosthetic valve endocarditis. function or cardiac failure or both in 11 patients; neurological complications with coma was the cause of death in five patients; and persistent sepsis in one patient.

\section{RESULTS OF COMBINED MEDICAL AND SURGICAL TREATMENT}

Thirty four of the 58 patients underwent repeat operation because of prosthetic valve endocarditis, and in some instances further operations were required. Thirty had late prosthetic valve endocarditis and four had early prosthetic valve endocarditis. Fifteen were operated on during an active stage. Table 5 lists the indications for operation in patients with infected prosthetic valves.

The main indication for surgery was progressive severe congestive heart failure caused by valve dysfunction, with or without persistent sepsis. One patient with Candida albicans infection of a Björk mitral valve died postoperatively of low cardiac output. In all cases operation included debridement of infected tissue. In four partial valve dehiscence was repaired without valve replacement; in 30 cases, correction of a haemodynamically important paravalvar leak had to be done by valve replacement, with reconstruction of aortic annulus in six cases, supraannular insertion of aortic prosthesis associated with coronary bypass in two cases, and insertion of a mitral prosthesis inside the atrial cavity in two cases.

\section{OPERATIVE MORTALITY}

Fourteen ( $41 \%$ ) patients died: nine from low cardiac output, three from neurological complications, one from severe septicaemia, and one from ventricular arrhythmias.

Many of the 20 patients who survived had early postoperative complications (table 6 ). The most frequent were persistent sepsis (5) and early prosthetic valve dehiscence (6) (three because of infection and three mechanical failures); three had a repeat valve replacement-one survived and two died. There 
Table 6 Early postoperative complications in 20 survivors two months after operation for prosthetic valve endocarditis (PVE)

\begin{tabular}{lll}
\hline Complications & No patients & $\%$ \\
\hline Persistent sepsis: & 5 & \\
Staphylococcus & 2 & \\
Gram negative bacteria & 1 & $25 \%$ \\
Candida albicans & 1 & \\
$\quad$ Negative blood culture & 1 & \\
Early prosthetic valve dehiscence & $6^{\star}$ & $30 \%$ \\
$\quad$ Infection & 3 & \\
Mechanical & 2 & $35 \%$ \\
Cerebral emboli & 2 & \\
Ventricular arrhythmia & 2 & \\
Complete heart block & 1 & \\
Mediastinal infection & & \\
\hline
\end{tabular}

*Three recurrent valve replacement, two deaths, and one survivor.

were two types of major complications in the 18 patients who survived for more than two months after operation: persistent sepsis (3) (two survived and one died after repeat prosthetic valve replacement because of major valve dehiscence) and late prosthetic or periprosthetic leak (6) (two minor and four major requiring subsequent reoperation with three deaths from low cardiac output.

So 14 are alive after operation. Eleven were followed (six with aortic and five with mitral valve replacement) (table 7).

\section{PROGNOSIS}

We compared the 16 survivors with the 37 patients who died (table 8) to determine what factors were important to outcome. Five patients were lost to follow up (three survivors with combined medical and surgical treatment and two survivors with medical treatment). Congestive heart failure occurred in $94 \%(35 / 37)$ of those who died and in $50 \%(8 / 16)$ of survivors $(\mathrm{p}<0.01)$.

Seventy eight per cent $(11 / 14)$ of patients with bacteria sensitive to antibiotics survived and $21 \%$ (3/14) died; whereas $20 \%(4 / 20)$ of patients with resistant bacteria survived and $80 \%(16 / 20)$ died $(\mathrm{p}<0.025)$.

Outcome was better when infection was restricted to the prostheses $(13 / 21)$ or $61 \%$ mortality compared with $86 \%(20 / 23)$ mortality in extensive lesions.

Mortality from early prosthetic valve endocarditis was much higher (11/11) than that in patients with late prosthetic valve endocarditis $(61 \%(26 / 42))$.

A combination of medical and surgical treatment was associated with a slight improvement in outcome: $35 \%(11 / 31)$ vs $22 \%(5 / 22)$ in the medically treated group $(\mathrm{p}<0.05)$.

Mortality in patients with neurological complications $(74 \%)$ was not different from that in patients without such complications $(72 \%)$.

Table 7 Clinical results in 11 survivors after surgical treatment for prosthetic valve endocarditis. Follow up period $18-62$ months (mean 41 months)

\begin{tabular}{llllll}
\hline Result & NYHA grade & CTR & ECG & Aortic (6) & Mitral (5) \\
\hline Excellent & I-II & Normal & Normal & & 1 \\
Good & I-II & Increased & Moderately altered & 6 & 4 \\
\hline
\end{tabular}

CTR, cardiothoracic ratio; NYHA, New York Heart Association.

Table $8 \quad \chi^{2}$ test to compare mortality and survival associated with various prognostic features

\begin{tabular}{|c|c|c|c|}
\hline & Survivors (16) & Deaths (37) & $\chi^{2}$ test \\
\hline PVE with congestive heart failure & 8 & 35 & $\mathrm{p}<0.01$ \\
\hline $\begin{array}{l}\text { Sensitive bacteria } \\
\text { Resistant bacteria }\end{array}$ & $\begin{array}{r}11 \\
4 \\
\end{array}$ & $\begin{array}{r}3 \\
16 \\
\end{array}$ & $\mathrm{p}<0.025$ \\
\hline $\begin{array}{l}\text { Active PVE } \\
\text { Healed PVE }\end{array}$ & $\begin{array}{r}3 \\
13\end{array}$ & $\begin{array}{l}20 \\
17\end{array}$ & $p<0.05$ \\
\hline $\begin{array}{l}\text { Infection localised to prostheses } \\
\text { Extension of infection to myocardium or wall of great } \\
\text { vessels }\end{array}$ & $\begin{array}{l}8 \\
3\end{array}$ & $\begin{array}{l}13 \\
20\end{array}$ & $p<0.05$ \\
\hline $\begin{array}{l}\text { PVE with CNS complications } \\
\text { PVE without CNS complications }\end{array}$ & $\begin{array}{r}4 \\
12\end{array}$ & $\begin{array}{l}11 \\
26\end{array}$ & NS \\
\hline $\begin{array}{l}\text { Early PVE } \\
\text { Late PVE }\end{array}$ & $\begin{array}{r}0 \\
16 \\
\end{array}$ & $\begin{array}{l}11 \\
26 \\
\end{array}$ & $p<0.01$ \\
\hline $\begin{array}{l}\text { Medical treatment } \\
\text { Combined medical surgical treatment }\end{array}$ & $\begin{array}{r}5 \\
11\end{array}$ & $\begin{array}{l}17 \\
20\end{array}$ & $p<0.05$ \\
\hline
\end{tabular}

CNS, central nervous system; PVE, prosthetic valve endocarditis. 


\section{Discussion}

Prosthetic valve endocarditis is a serious and increasingly common complication of heart valve replacement; it is reported in $1-9,4 \%$ of patients with prosthetic valve replacement. ${ }^{1-5}$ The high overall frequency $(5.9 \%)$ in our series may be the result of inadequate prophylaxis. Clinical diagnosis is established by fever, leucocytosis, haematuria, cutaneous signs, splenomegaly, and the discovery at auscultation of new regurgitant murmurs. ${ }^{46}$ In $60 \%$ of our patients blood cultures were positive. The rate of negative blood cultures was high because many of our patients were referred from other hospitals and were already on antibiotics. Immunological abnormalities are a useful diagnostic feature in patients with negative blood cultures. ${ }^{7-9}$

Like other workers, ${ }^{610-13}$ we too found that streptococci were the most common causal microorganisms-followed by staphylococci, Gram negative bacteria, and fungi. Streptococci commonly cause late prosthetic valve endocarditis, often after treatment, whereas staphylococci, Gram negative bacteria, and Candida species are more important in early prosthetic valve endocarditis. ${ }^{3614}$ The organisms are mainly acquired in the operating rooms or in the intensive care unit. ${ }^{3}$

There are differences in pathological findings between mechanical valves and bioprosthetic valves. In mechanical valves endocarditis is often associated with an infection behind the site of attachment of the prosthesis, resulting in ring abscess and dehiscence of the prosthesis. ${ }^{15}$ Extension of infection to adjacent cardiac structures is very common and it may cause a myocardial abscess, disruption of the atrioventricular conduction system, or fistulas into the right heart or pericardium. ${ }^{15}$ Vegetations are also common and they can be extensive, particularly in fungal infection. Ferrans et al found that bioprosthetic infection is usually localised to the cusps. ${ }^{16}$

Renal failure and nephrotic syndrome are rare, ${ }^{17}$ and due to a focal or diffuse glomerlonephritis and associated with immune complex in the serum and immunoglobulin deposits on the capillary wall. ${ }^{18}$

Mortality from prosthetic valve endocarditis is high, ranging from $35 \%$ to $71 \% .{ }^{13-511-13} \mathrm{~A}$ new or an increased regurgitant murmur and the presence of congestive heart failure ${ }^{\mathbf{4}}$ are associated with a very high mortality. We found $95 \%$ mortality in patients with heart failure compared with $50 \%$ in patients without congestive heart failure. The type of micro-organism is a major factor; patients with prosthetic valve endocarditis caused by less pathogenic organisms that are susceptible to antibiotic treatment respond better than those with prosthetic valve endocarditis caused by more invasive, anti- biotic resistant bacteria. ${ }^{4611}$ In the present series the mortality rate in streptococcal prosthetic valve endocarditis was $21 \%$ compared with $80 \%$ in nonstreptococcal prosthetic valve endocarditis.

Extension of infection into the valve seat and adjacent tissues may result in partial or complete valve dehiscence, myocardial abscess, disruption of the atrioventricular conduction system, or fistulas into the right heart or pericardium. Our results and those of others ${ }^{61920}$ suggest that invasion of the myocardium is associated with an increased mortality.

Mortality also varies with the time of onset of prosthetic valve endocarditis; most reports emphasise that prognosis is better in late prosthetic valve endocarditis ${ }^{6101213}$ than in early infection. ${ }^{112021}$ This difference may be attributed to the predominance of streptococcal infection in late prosthetic valve endocarditis and the more pathogenic organisms seen in early prosthetic valve endocarditis, to immediate recovery from the operation, and to altered host resistance produced by the pump oxygenator. ${ }^{223}$ Neurological complications are an important cause of mortality and morbidity. ${ }^{6}$ Twenty five of the 33 deaths reported by Masur and Johnson were attributed to cardiac causes and eight to central nervous system events. ${ }^{4}$

Operation has dramatically improved the prognosis of prosthetic valve endocarditis. Gardner et al combined the results of treatment for prosthetic valve endocarditis of three published series and demonstrated a higher survival rate with combined valve replacement and antibiotic treatment compared with medical treatment alone. ${ }^{24}$ Stinson et al successfully treated 12 of 17 patients with active prosthetic valve endocarditis by combined valve replacement and antimicrobial treatment; operative mortality was $24 \% .{ }^{25}$ These investigators recommend intervention irrespective of the stage of endocarditis.

Medical treatment alone should be used only in cases of prosthetic valve endocarditis caused by antibiotic sensitive micro-organisms, with unimportant or no prosthetic dysfunction, and when congestive heart failure and embolic events are absent. ${ }^{26}$ Early operation combined with antibiotic treatment should be considered in all other cases. ${ }^{625}$ The main indications for operation are listed below: (a) Congestive heart failure with coexistent prosthetic dysfunction that does not respond to medical treatment. ${ }^{1327}(b)$ Persistent sepsis after 7-10 days of appropriate antibiotic treatment or relapse after appropriate treatment or when fungal endocarditis is diagnosed. (c) Occurrence of an arterial embolus when echocardiography demonstrates residual vegetations ${ }^{13}$ or in the absence of abnormal echocardiographic findings when more than one arterial 
embolus occurs, or the presence of a single embolus which if exacerbated by a further embolic insult might result in irreversible neurological damage. ${ }^{61219}(d)$ Conduction system abnormalities almost always indicate an annular abscess with extension to the septum ${ }^{13}$ and such lesions do not respond to medical treatment. ${ }^{1928}(e)$ The appearance of new murmurs caused by fistulas into the right heart or pericardium or by septal rupture. ${ }^{26}$

\section{Conclusion}

The high mortality in prosthetic valve endocarditis is mainly the result of congestive heart failure which is usually caused by prosthetic valve dysfunction. Mortality in early and late prosthetic valve endocarditis is reduced by prompt surgical intervention and adequate antibiotic treatment.

\section{References}

1 Anger P, Marquis G, Dyrda I, Martineau JP, Solymoss CB. Infective endocarditis update experience from a heart hospital. Acta Cardiol (Brux) 1981;2:105-23.

2 Calderwood SB, Swinski LA, Waternaux CM, Karchmer AW, Buckley MJ. Risk factors for the development of prosthetic valve endocarditis. Circulation 1985;1:31-7.

3 Ivert TA, Dismukes WE, Cobbs CG, Blackstone EH, Kirklin JW, Bergdahl LAL. Prosthetic valve endocarditis. Circulation 1984;2:223-32.

4 Masur H, Johnson WD. Prosthetic valve'endocarditis. $J$ Thorac Cardiovasc Surg 1980;80:31-7.

5 Vahanian A, Prost JF, Richard C, Dewilde J, Acar J. Endocardites infectieuses chez les porteurs de prothèses valvulaires. Arch Mal Coeur 1982;75: 971-9.

6 Karchmer AW, Dismukes WE, Buckley MJ, Austen WG. Late prosthetic valve endocarditis. Clinical features influencing therapy. $A m J$ Med 1978;64: 199-206.

7 Carson DA, Bayer AS, Eisenberg RA, Lawrence S, Theofilopoulos AN. IgG rheumatoid factor in subacute bacterial endocarditis: relationship to IgM rheumatoid factor and circulating immune complexes. Clin Exp Immunol 1978;31:100-3.

8 Herreman G, Godeau P, Cabane J, Digeon M, Bach JF. Complexes immuns circulants et endocardites infectieuses. A propos de 64 observations. Ann Med Interne (Paris) 1978;129:387-97.

9 Ben Ismail M, Hannachi N. Etude immunologique des endocardites infectieuses et du rhumatisme articulaire aigu. Tunis: Editions Techniques Spécialisées 1984.

10 Baumgartner WA, Miller DC, Reitz BA, et al. Surgical treatment of prosthetic valve endocarditis. Ann Thorac Surg 1983;35:87-104.

11 Rossiter SG, Stinson EB, Oyer PE, et al. Prosthetic valve endocarditis. Comparison of heterograft tissue valves and mechanical valves. $J$ Thorac Cardiovasc Surg 1978;76:795-803.

12 Slaughter L, Morris JE, Starr A. Prosthetic valvular endocarditis: a 12 year review. Circulation 1973;47: 1319-26.

13 Wilson WR, Jaumin PM, Danielson GK, Giuliana ER, Washington JA, Geraci JE. Prosthetic valve endocarditis. Ann Intern Med 1975;82:751-6.

14 Sweeney MS, Reul GJ, Cooley DA, et al. Comparison of bioprosthetic and mechanical valve replacement for active endocarditis. $J$ Thorac Cardiovasc Surg 1985;90:676-80.

15 Mayer KH, Schoenbaum SC. Evaluation et conduite à tenir dans l'endocardite sur prothèses valvulaires. Acquisitions Nouvelles en Pathologie Cardiovasculaire 1983;25:59-79.

16 Ferrans VJ, Boyce SW, Billingham ME. Infection of gluteraldehyde-preserved porcine valve heterografts. Am J Cardiol 1979;43:1123-34.

17 Witchitz S. Les endocardites infectieuses. Encycl Med Chirug Paris Coeur 11009,A.10,9.

18 Morel Maroger L, Sraer JD, Herreman G, Godeau P. Kidney in subacute endocarditis; pathological and immunofluorescence findings. Arch Pathol 1972;94: 205-13.

19 Arnett EN, Roberts WC. Prosthetic valve endocarditis. A study of 18 patients at necropsy. Am J Cardiol 1975;35:120.

20 Madison J, Wang K, Gobel FL, Edwards JE. Prosthetic aortic valvular endocarditis. Circulation 1975;51:940-9.

21 Dismukes WE, Karchmer AW, Buckley MJ, Austen WG, Swarts MN. Prosthetic valve endocarditis. An analysis of 38 cases. Circulation 1973;48:365-77.

22 Nunez L, de la Liana R, Auguado MG, Iglesias A, Larrea JL, Celemin D. Bioprosthetic valve endocarditis, indicators for surgical intervention. Ann Thorac Surg 1983;35:262-70.

23 Magilligan D Jr, Quinn EL, Davila JC. Bacteremia endocarditis and the Hancock valve. Ann Thorac Surg 1977;24:508-18.

24. Gardner P, Saffle Jr, Shoenbaum SC. Management of prosthetic valve endocarditis. In: Duma RJ, ed. Infections of prosthetic valves and vascular grafts: prevention, diagnosis and treatment. Baltimore: University Park Press, 1977:123.

25 Stinson EB, Criepp RB, Vosti K, Copeland JG, Shumway NE. Operative treatment of active endocarditis. J Thorac Cardiovasc Surg 1976;71:659-65.

26 Ben Ismail M, Abid F, Hannachi N, Boughzela E. Les endocardites infectieuses sur prothèses valvulaires. Jean ACAR; Cardiopathies valvulaires acquises 1985. Paris: Flammarion. Medecine-Sciences 1985:630-6.

27 Johnson WD Jr. Prosthetic valve endocarditis. In: Kaye D, ed. Infective endocarditis. Baltimore: University Park Press, 1976:129-42.

28 Anderson DJ, Bulkley BH, Hutchins GM. A clinico pathologic study of prosthetic valve endocarditis in 22 patients: morphologic basis for diagnosis and therapy. Am Heart J 1977;94:325-32. 